\title{
Melatonin attenuates palmitic acid-induced mouse granulosa cells apoptosis via endoplasmic reticulum stress
}

\author{
Zhi Chen ${ }^{1}$, Lanjie Lei ${ }^{2,3}$, Di Wen $^{1}$ and Lei Yang ${ }^{3,4^{*}}$
}

\begin{abstract}
Background: Palmitic acid (PA), the main component of dietary saturated fat, causes apoptosis in many cell types, including mouse granulosa cell. Melatonin, an important endogenous hormone, has beneficial effects on female reproductive processes. Since elevated PA levels are present in follicular fluid (FF) of patients with infertility and are shown to be toxic for granulosa cells, we investigated the molecular mechanisms of PA toxicity in mouse granulosa cells and explored the effects of melatonin on PA-induced apoptosis.

Methods: Granulosa cells from immature female mice were cultured for $24 \mathrm{~h}$ in medium containing PA and/or melatonin. Then, the effects of PA alone or combined with melatonin on viability, apoptosis and endoplasmic reticulum (ER) stress in granulosa cells were detected by methyl thiazolyl tetrazolium (MTT) assay, flow cytometry assay and western blot. After $48 \mathrm{~h}$ of PA and/or melatonin treatment, the concentrations of estradiol (E2) and progesterone (P4) in the culture supernatants were measured with ELISA kits.

Results: In this study, we explored the effects of melatonin on cell viability and apoptosis in PA-treated mouse granulosa cells and uncovered the signaling pathways involved in these processes. Our results showed that 200800 MM PA treatment reduces cell viability, induces cell apoptosis, enhances the expression of apoptosis-related genes (Caspase 3 and B-cell lymphoma-2 (BCL-2) associated $X$ protein (BAX)), and activates the expression of ER stress marker genes (glucose-regulated protein 78 (GRP78) and CCAAT/enhancer binding protein homologous protein (CHOP)). Melatonin treatment (1-10 $\mu \mathrm{M})$ suppresses $400 \mu \mathrm{M}$ PA-induced cell viability decrease, cell apoptosis, Caspase 3 activation, and BAX, CHOP, and GRP78 expression. In addition, we found that $10 \mu \mathrm{M}$ melatonin successfully attenuated the $400 \mu \mathrm{M}$ PA-induced estrogen (E2) and progesterone (P4) decreases.
\end{abstract}

Conclusions: This study suggests that PA triggers cell apoptosis via ER stress and that melatonin protects cells against apoptosis by inhibiting ER stress in mouse granulosa cells.

Keywords: Palmitic acid, Melatonin, Endoplasmic reticulum stress, Mouse granulosa cell, Apoptosis

\section{Background}

Palmitic acid (PA) is one of the most common fatty acids in animal and human follicular fluid (FF) and blood serum [1-3]. The PA level in mammalian FF is reported to be approximately $10^{-4} \mathrm{M}[3-5]$. Recently, increasing evidence has shown that elevated PA levels may be associated with infertility in humans [6, 7]. Animal model studies have

\footnotetext{
* Correspondence: yangleigeili@163.com

${ }^{3}$ Key Laboratory of System Bio-medicine of Jiangxi Province, Jiujiang

University, Jiujiang 332000, Jiangxi, China

${ }^{4}$ College of Basic Medical Science, Jiujiang University, Jiujiang 332000, Jiangxi, China

Full list of author information is available at the end of the article
}

reported relations between higher PA levels and decreased rates of fertilization, cleavage, and blastocyst formation $[3,8$, 9]. Granulosa cells play essential roles in follicular development, oocyte maturation and sex hormone secretion [1012]. The exposure of granulosa cells to PA inhibits cell proliferation and decreases steroidogenesis. PA impairs fertility by suppressing human granulosa cell survival and inducing apoptosis [13, 14]. Therefore, ameliorating the toxic effects of PA on granulosa cells may be an effective method to treat human infertility. To date, the exact molecular mechanism of PA-induced granulosa cell apoptosis, however, has not been fully understood. Our previous studies have suggested 
that ER stress is involved in granulosa cell apoptosis $[15,16]$. However, it remains elusive whether ER stress is involved in PA-induced granulosa cell apoptosis.

The ER plays an important role in the folding, transport, and processing of newly synthesized proteins and the biosynthesis of cholesterol, steroids, and other lipids, which is essential for the maintenance of homeostasis in organisms. The accumulation of unfolded or misfolded proteins in the ER lumen can affect ER homeostasis and trigger a protective mechanism known as the unfolded protein response (UPR). Three ER transmembrane proteins, protein kinase RNA (PKR)-like ER kinase (PERK), inositol-requiring enzyme-1 (IRE-1), and activating transcription factor-6 (ATF6), are involved in ER stress and are associated with glucose-regulated protein 78 (GRP78, an ER chaperone) [17]. The primary objective of the UPR is to re-establish homeostasis and alleviate ER stress by increasing the protein folding capacity and decreasing the unfolded protein load. However, when ER stress fails to manage misfolded and unfolded proteins, cell apoptosis is induced [18]. Previous studies have reported that melatonin inhibits cell apoptosis by attenuating ER stress [19-21].

Melatonin is an important endogenous hormone involved in the biological clock, the circadian rhythm and reproductive physiology. Its actions are mediated via two types of receptors, MT1 and MT2, which are expressed in not only the pineal gland but also other parts of the organism, including granulosa cells [22-24]. Increasing evidence from in vitro cultured cell and animal studies has shown the beneficial effects of melatonin on female reproductive processes, such as follicle growth $[25,26]$, embryonic development [27] and oocyte maturation [25]. Dynamic changes in the porcine intrafollicular melatonin concentration correlate with the progress of follicular atresia. Normally, melatonin levels might positively correlate with follicular growth [28]. High levels of melatonin were found in human preovulatory FF [29]. A recent study revealed that the intrafollicular melatonin concentration decreases as follicular atresia progresses, whereas the percentage of apoptotic granulosa cells increases [26]. The initiation of granulosa cell apoptosis during porcine follicular atresia may be related to an ER stress response, and melatonin can inhibit apoptosis and stimulate progesterone production by granulosa cells [26, 30]. PA has been demonstrated to induce apoptosis in human granulosa cells [13]. However, the effects and mechanisms of melatonin on PA-induced granulosa cell apoptosis have never been studied.

In this study, we aimed to explore the potential molecular mechanisms of PA-induced apoptosis, to detect the effects of melatonin on PA-induced apoptosis, and to examine whether this process is related to ER stress in mouse granulosa cells.

\section{Materials and methods}

\section{Chemicals and mice}

All chemicals were purchased from Sigma-Aldrich (St. Louis, MO, USA) unless otherwise stated. Female Kunming White outbred strain mice (21-28 days old) were obtained from the Experimental Animal Center of Jiujiang University. All mice were fed a typical diet of lab chow and housed in a single room under conditions of constant temperature $\left(25-28 \pm 2{ }^{\circ} \mathrm{C}\right)$, humidity $(55 \pm 5 \%)$, and lighting (12 h light, $12 \mathrm{~h}$ dark cycle). All procedures were approved by the Committee for the Ethics on Animal Care and Experiments of Jiujiang University (approval No. SYXK(GAN)2017-0001).

\section{Granulosa cell collection, culture and treatment}

Immature female mice $(n=285)$ were intraperitoneally injected with $8 \mathrm{IU}$ pregnant mare serum gonadotrophin (PMSG) (Ningbo Sansheng, Ningbo, China) to facilitate granulosa cell proliferation. After $44 \mathrm{~h}$, primary mouse granulosa cells were isolated and cultured as described previously [31]. Briefly, the ovaries were collected, and granulosa cells were released by puncturing the follicles with 26-gauge needles under sterile conditions. Then, the granulosa cells were washed and collected by brief centrifugation, and cell viability was determined by trypan blue exclusion. Finally, the cells were cultured in Dulbecco's modified Eagle's medium/Ham's F 12 nutrient mixture (DMEM/F12, HyClone, UT, USA) containing $100 \mathrm{IU} / \mathrm{mL}$ penicillin, $100 \mu \mathrm{g} / \mathrm{mL}$ streptomycin, and $10 \%$ fetal bovine serum (FBS, Corning, USA) at $37^{\circ} \mathrm{C}$ in $5 \% \mathrm{CO}_{2}$ and $95 \% \mathrm{O}_{2}$ for $48 \mathrm{~h}$.

Melatonin was freshly dissolved in absolute ethanol to produce a $100 \mathrm{mM}$ stock solution and then kept at $4{ }^{\circ} \mathrm{C}$. Before application, stock solution was further diluted in culture medium. 4-Phenylbutyrate (4-PBA, ER stress inhibitor), and thapsigargin (TG, ER stress agonist) were prepared in dimethyl sulfoxide (DMSO) and immediately diluted with culture medium before the experiment. The final concentration of DMSO in the incubation mixture did not exceed $0.1 \%$. When the cells reached $70-80 \%$ confluence, they were exposed to increasing concentrations of melatonin $(0.1-100 \mu \mathrm{M})$ or PA $(100-800 \mu \mathrm{M})$. In another experiment, cells were exposed to TG $(500 \mathrm{nM})$ and PA $(400 \mu \mathrm{M})$ in the absence or presence of 4-PBA $(500 \mathrm{nM})$ and melatonin $(10 \mu \mathrm{M})$ (Fig. 1). Standard conditions were maintained for the control group. After incubation for $24 \mathrm{~h}$, the cells were collected to assess cell viability, apoptosis, and Caspase 3 activity, and western blotting was performed.

\section{Cell proliferation assay}

Granulosa cells ( $n=35$ mice) were plated into 96-well plates at $1 \times 10^{5}$ cells $/ \mathrm{mL}$. After treatment, the cells were treated with $0.5 \mathrm{mg} / \mathrm{mL}$ MTT and then incubated for an additional $4 \mathrm{~h}$. At the end of the experiments, the cell growth medium was replaced with $150 \mu \mathrm{L}$ DMSO and 


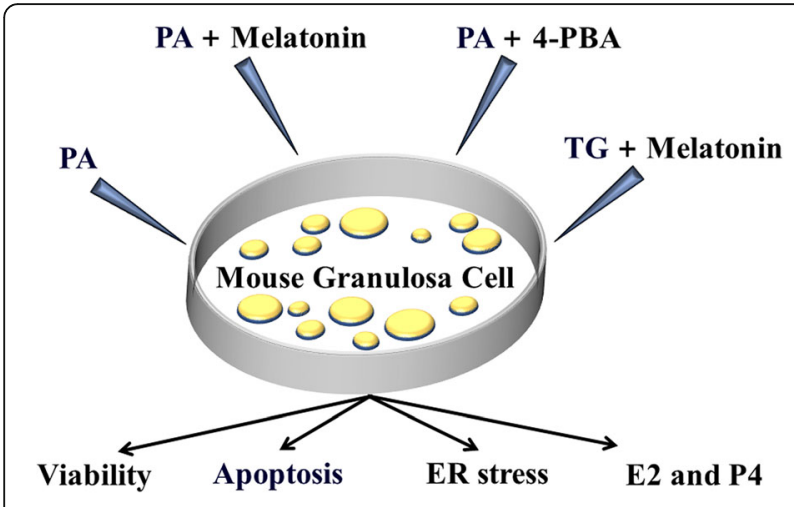

Fig. 1 Schematic of the experimental design. Mouse granulosa cells were collected from the ovaries of immature female mice and then treated with PA, PA + melatonin, PA + 4-PBA or TG + melatonin to explore the mechanism of melatonin that protects against PAinduced cell apoptosis

colorimetric measurements were performed with an ELISA plate reader at $570 \mathrm{~nm}$ [32]. The experiments were performed in triplicate (about 12 mice in a group). Cell viability was calculated as follows: relative viability $(\%)=[$ A450 (treated) - A450 (blank) $] /[$ A450 (control) A450 (blank)] $\times 100 \%$.

\section{Measurement of the estradiol and progesterone levels}

Briefly, granulosa cells $(n=45$ mice, about 15 mice in each group) were cultured in DMEM/F12 for $48 \mathrm{~h}$. The cells were then incubated with PA, TG, 4-PBA or/and melatonin for $48 \mathrm{~h}$. After $48 \mathrm{~h}$ of treatment, the mouse granulosa cells were counted. Then, the concentrations of E2 and P4 in the culture supernatants were measured with ELISA kits (Ji Yin Mei, Wuhan, China) according to the manufacturer's instructions. The minimum detectable concentration of E2 was $10 \mathrm{pg} / \mathrm{mL}$. The intra- and interassay coefficients of variation were $<10$ and $<15 \%$, respectively. The minimum detectable concentration of $\mathrm{P} 4$ was $0.25 \mathrm{ng} / \mathrm{mL}$. The intra- and interassay coefficients of variation were $<10$ and $<15 \%$, respectively. Each sample was measured in triplicate.

\section{Cell apoptosis measurement}

The apoptosis level of cells $(n=55$ mice, about 18 mice in each group) was quantified with an Annexin V/PI Apoptosis Analysis Kit according to the manufacturer's instructions. The cells were analyzed using a fluorescence-activated cell sorter (Becton, Dickinson and Company, USA) within $1 \mathrm{~h}$ of staining. The proportion of early apoptotic cells was determined by measuring the percentage of Annexin V+/PIcells; the proportion of progressed apoptotic cells was obtained by determining the percentage of Annexin $\mathrm{V}+/ \mathrm{PI}+$ cells; the proportion of necrotic cells was detected by determining the percentage of Annexin $\mathrm{V}-/ \mathrm{PI}+$ cells and Annexin $\mathrm{V}-$ /PI- cells were considered surviving cells as previously reported [18].

\section{Western blot analysis}

After treatment, cells ( $n=150$ mice, about 50 mice in each group) were collected and washed with an ice-cold phosphate buffer solution (PBS) and lysed with radioimmunoprecipitation assay (RIPA) lysis buffer containing $1 \%$ phenylmethylsulfonyl fluoride (PMSF), and the total protein concentration was measured by a bicinchoninic acid (BCA) assay according to the manufacturer's instructions. For each sample, $30 \mu \mathrm{g}$ total protein was separated on a $12 \%$ polyacrylamide gel before being transferred to polyvinylidene difluoride (PVDF) membranes (Millipore, Bedford, MA, USA). After blocking in Tris-buffered saline-Tween-20 (TBST) supplemented with $5 \%$ skim milk at $25^{\circ} \mathrm{C}$ for $1 \mathrm{~h}$, the membranes were incubated overnight at $4{ }^{\circ} \mathrm{C}$ with a primary antibody (Additional file 1: Table S1). After washing, the membranes were incubated with a secondary antibody conjugated with horseradish peroxidase at $37^{\circ} \mathrm{C}$ for $30 \mathrm{~min}$. Finally, the immunoreactive bands were visualized using a Super Signal West Pico kit (Proteintech, Wuhan, China) with a Bio-Rad imaging system (Bio-Rad, CA, USA) according to the manufacturer's instructions. The protein band densities were semiquantified by densitometric analysis using ImageJ software 1.48 (Bethesda, MD, USA).

\section{Statistical analyses}

All experiments were repeated three times for each group, and the data are presented as the mean \pm SEM. The data were analyzed by ANOVA, followed by Fisher's least significant difference test and independent samples Student's t test, with SPSS software, version 13.0 (SPSS, Chicago, IL, USA).

\section{Results}

\section{Effects of PA on cell viability and apoptosis in mouse granulosa cells}

The effect of PA on mouse granulosa cells was examined by treatment with $100-800 \mu \mathrm{M}$ PA for $24 \mathrm{~h}$. The MTT results showed that PA had very little effect at the low doses of $100 \mu \mathrm{M}$, while $200-800 \mu \mathrm{M}$ PA significantly inhibited cell viability (Fig. 2a). We further analyzed the granulosa cell apoptosis induced by PA via flow cytometry. The results revealed that compared with the control treatment, PA treatment increased the percentage of apoptotic granulosa cells in a dose-dependent manner (Fig. 2b), and the IC50 value was approximately $400 \mu \mathrm{M}$.

\section{Effect of PA on caspase 3 activity and BAX expression in mouse granulosa cells}

To further explore the mechanism of PA-induced cell apoptosis in granulosa cells, the expression of apoptosis-related genes (Caspase 3 and BAX) was measured by a colorimetric assay and western blot analysis after treatment with $100-800 \mu \mathrm{M}$ PA for $24 \mathrm{~h}$. The results suggested that the expression patterns of Caspase 3 and BAX were similar, and the expression of both molecules increased in a 

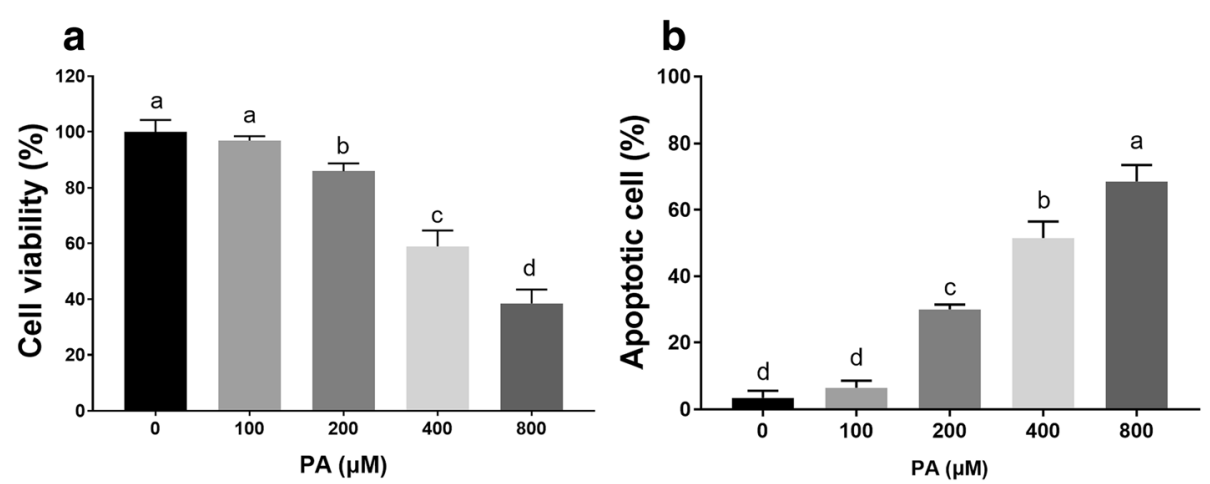

Fig. 2 Effect of PA on the growth and apoptosis of mouse granulosa cells. a Cells were treated with different concentrations (100-800 $\mu \mathrm{M})$ of PA for $24 \mathrm{~h}$ and then processed for the cell activity analysis. $\mathbf{b}$ Cells were treated with different concentrations (100-800 $\mu \mathrm{M})$ of PA for $24 \mathrm{~h}$ and then processed for an apoptosis assay. Data are presented as the mean \pm SEM of three independent experiments. Bars with different letters are significantly different $(p<0.05)$

dose-dependent manner after treatment for $24 \mathrm{~h}$. The minimum effective dose was $200 \mu \mathrm{M}$ PA (Fig. 3).

\section{Effect of PA on GRP78 and CHOP expression in mouse granulosa cells}

We detected the expression of ER stress marker genes (GRP78 and CHOP) after treatment with 100-800 $\mu \mathrm{M}$ PA for $24 \mathrm{~h}$. The results showed that PA treatment at a concentration up to $400 \mu \mathrm{M}$ significantly induced the expression of GRP78 in a dose-dependent manner. However, $800 \mu \mathrm{M}$ PA decreased GRP78 expression at 24h (Fig. 4a and b). CHOP expression was significantly induced by $200 \mu \mathrm{M}$ PA, and $800 \mu \mathrm{M}$ PA induced the highest expression levels at 24 h (Fig. 4a and c).

\section{Melatonin attenuated the cytotoxicity of PA in mouse granulosa cells}

We first detected the $0.1-100 \mu \mathrm{M}$ melatonin on the viability of mouse granulosa cells at $24 \mathrm{~h}$. The results showed that melatonin alone had no effect on the viability of granulosa cells at concentrations up to $10 \mu \mathrm{M}$, whereas the $100 \mu \mathrm{M}$ melatonin group showed decreased cell viability compared to the control group (Fig. 5a). Compared with the $400 \mu \mathrm{M}$ PA group, the 1 and $10 \mu \mathrm{M}$ melatonin groups exhibited a dose-dependent enhancement in cell viability; however, the $100 \mu \mathrm{M}$ melatonin group had lower cell viability than the $10 \mu \mathrm{M}$ group and higher viability than the PA-treated group (Fig. 5b).

\section{Melatonin inhibited PA-induced apoptosis in mouse granulosa cells}

To detect the cytoprotective effect of melatonin on PA-treated granulosa cells, cells were treated with $400 \mu \mathrm{M}$ PA and $0.1-100 \mu \mathrm{M}$ melatonin for $24 \mathrm{~h}$. The flow cytometry results showed that melatonin treatment obviously reduced the cellular apoptosis rate, and the lowest effective concentration was $1 \mu \mathrm{M}$ (Fig. 6a). We also detected Caspase 3 and BAX
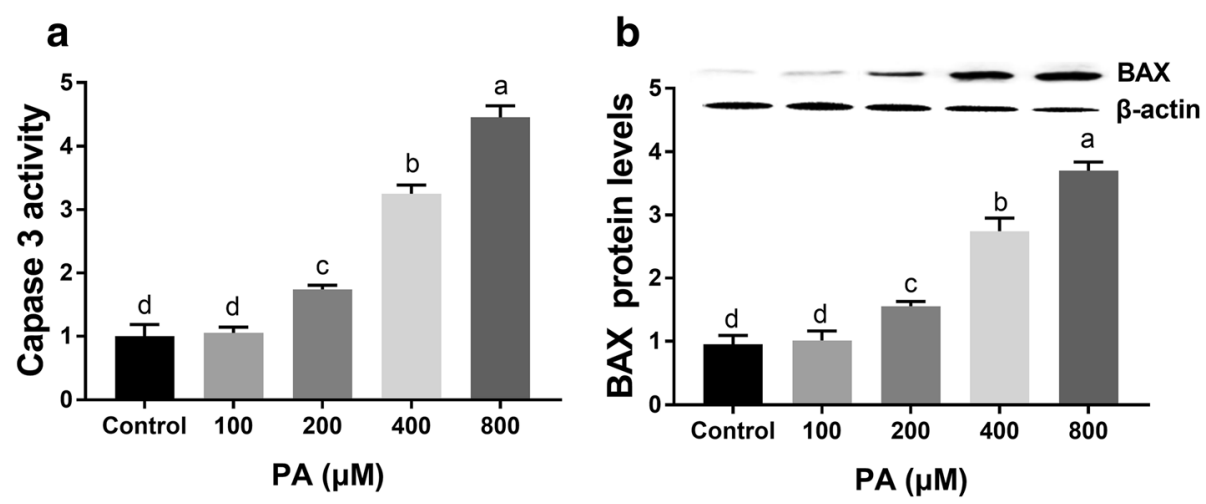

Fig. 3 Effect of PA on apoptosis-related gene expression in mouse granulosa cells. a Caspase 3 activity in mouse granulosa cells after treatment with different doses of PA (0-800 $\mu \mathrm{M})$ for $24 \mathrm{~h}$. b Relative BAX expression in mouse granulosa cells after treatment with different doses of PA (0$800 \mu \mathrm{M})$ for $24 \mathrm{~h}$. BAX expression was normalized to the level of $\beta$-actin expression. The statistical analysis results are shown in the bar graphs. Data are presented as the mean \pm SEM of three independent experiments. Bars with different letters are significantly different $(p<0.05)$ 

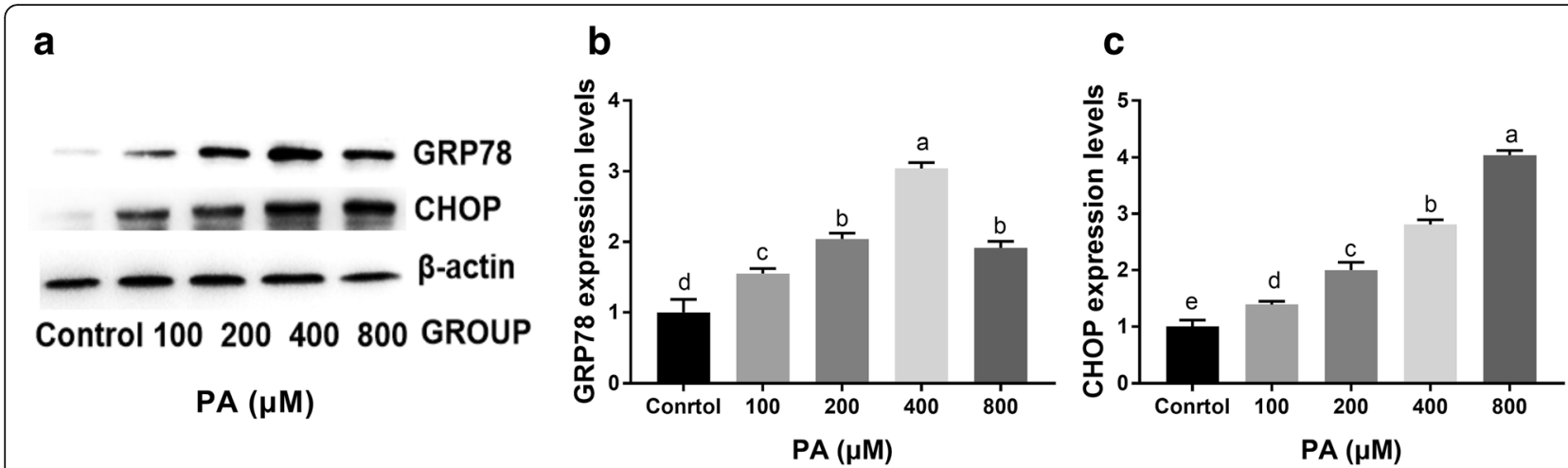

Fig. 4 Effect of PA on ER stress-related protein expression in mouse granulosa cells. a Expression of GRP78 and CHOP in mouse granulosa cells after treatment with different doses of PA $(100-800 \mu \mathrm{M})$ for $24 \mathrm{~h}$. b Relative expression of GRP78 after treatment with different doses of PA (100$800 \mu \mathrm{M})$ for $24 \mathrm{~h}$. c Relative expression of CHOP after treatment with different doses of PA (100-800 $\mu \mathrm{M})$ for $24 \mathrm{~h}$. Protein expression was normalized to the level of $\beta$-actin expression. The statistical analysis results are shown in the bar graphs. Data are presented as the mean \pm SEM of three independent experiments. Bars with different letters are significantly different $(p<0.05)$

expression by a colorimetric assay and western blot analysis. Similar to the flow cytometry results, these results revealed that melatonin treatment successfully reduced the Caspase 3 activity and BAX protein expression caused by $400 \mu \mathrm{M}$ PA (Fig. 6b and c).

\section{Melatonin suppressed PA-induced ER stress in mouse granulosa cells}

To detect the effect of melatonin on PA-induced ER stress, mouse granulosa cells were treated with $400 \mu \mathrm{M}$ PA and $0.1-100 \mu \mathrm{M}$ melatonin for $24 \mathrm{~h}$. Then, CHOP and GRP78 expression was detected by western blot analysis. The results showed that PA markedly enhanced the expression of GRP78 and CHOP, and these expression levels were attenuated by melatonin in a concentration-dependent manner up to a concentration of $10 \mu \mathrm{M}$ (Fig. 7).
4-PBA attenuated PA-induced cytotoxicity, apoptosis and ER stress in mouse granulosa cells

To confirm the role of ER stress in PA-mediated mouse granulosa cell apoptosis, cells were treated with PA and the ER stress inhibitor 4-PBA. The results revealed that 4-PBA significantly promoted cell viability and prevented the cell apoptosis caused by PA at $24 \mathrm{~h}$ (Fig. 8a-c). In addition, 4-PBA obviously reduced Caspase 3 activity and BAX expression (Fig. 8d-f). In addition, western blotting revealed that the expression levels of GRP78 and CHOP in the PA-treated cells were markedly decreased after treatment with 4-PBA (Fig. 8e-h).

Melatonin rescued TG-induced decreased cell viability, apoptosis, and ER stress in mouse granulosa cells

To detect the effect of melatonin on ER stress-induced cell apoptosis, we added $500 \mathrm{nM}$ TG to the culture medium to induce ER stress. Treatment with $10 \mu \mathrm{M}$
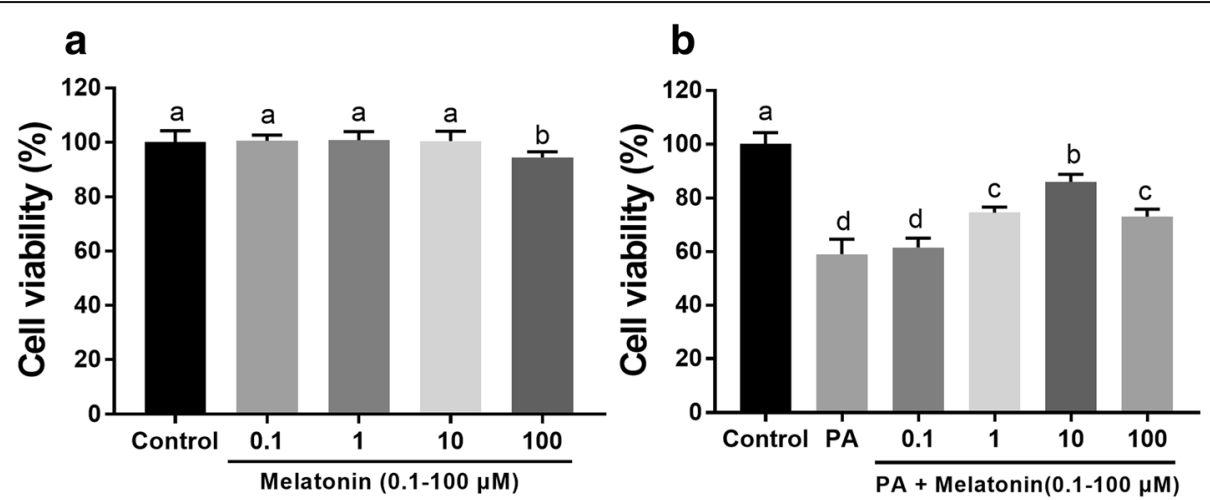

Fig. 5 Effects of melatonin on PA-induced mouse granulosa cell activity. a Cells were treated with different concentrations of melatonin (0.1$100 \mu \mathrm{M})$ for $24 \mathrm{~h}$ and then processed for cell activity analysis. $\mathbf{b}$ Cells were treated with different concentrations of melatonin (0.1-100 $\mu \mathrm{M})$ and $400 \mu \mathrm{M}$ PA for $24 \mathrm{~h}$. Data are presented as the mean \pm SEM of three independent experiments. Bars with different letters are significantly different $(p<0.05)$ 

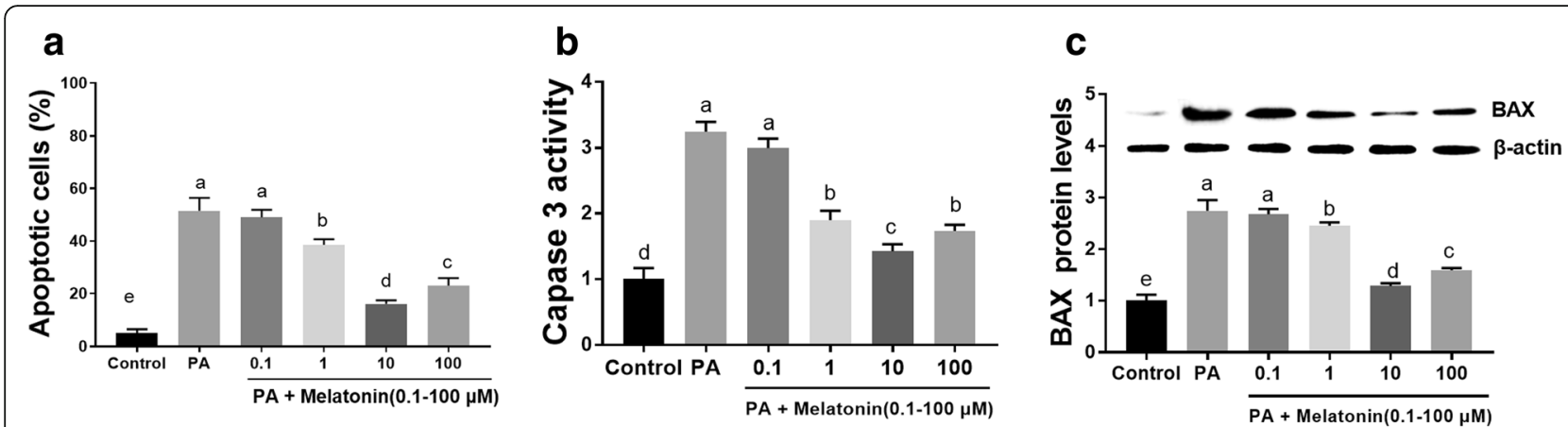

Fig. 6 Effects of melatonin on PA-induced mouse granulosa cell apoptosis and apoptosis-related gene expression. a Effects of different concentrations of melatonin (0.1-100 $\mu \mathrm{M})$ on PA-induced mouse granulosa cell apoptosis after $24 \mathrm{~h}$. $\mathbf{b}$ Caspase 3 activity in mouse granulosa cells after treatment with different concentrations of melatonin (0.1-100 $\mu \mathrm{M})$ and $400 \mu \mathrm{M}$ PA for 24 h. c Relative BAX expression in mouse granulosa cells after treatment with different concentrations of melatonin (0.1-100 $\mu \mathrm{M})$ and $400 \mu \mathrm{M}$ PA for $24 \mathrm{~h}$. BAX expression was normalized to the level of $\beta$-actin expression. The statistical analysis results are shown in the bar graphs. Data are presented as the mean \pm SEM of three independent experiments. Bars with different letters are significantly different $(p<0.05)$

melatonin significantly promoted cell viability and prevented the cell apoptosis induced by TG (Fig. 9a-c). The western blotting results indicated that melatonin reduced the protein levels of GRP78 and CHOP in the TG-treated mouse granulosa cells (Fig. 9e, g and h). We also detected the expression of Caspase 3 and BAX. The results showed that PA significantly increased the protein expression levels of Caspase 3 and BAX compared with the control treatment (Fig. 9d-f).

\section{Melatonin attenuated the decreases in the E2 and P4 levels in PA-treated mouse granulosa cells}

To assess the effects of melatonin on steroid hormones in PA-induced mouse granulosa cells, we measured the concentrations of E2 and P4 in the culture medium after PA and TG treatment. The results showed that $500 \mathrm{nM}$ TG and $400 \mu \mathrm{M}$ PA inhibited the expression of steroidogenic enzymes expression (Star, Cyp19a1 and Cyp11a1) and the production of steroid hormones (E2 and P4) (Fig. 10). In contrast, $10 \mu \mathrm{M}$ melatonin treatment slightly increased the expression of Star and Cyp11a1 but not Cyp19a1 and enhanced the synthesis of P4 (Fig. 10a-f). Additionally, melatonin increased the levels of E2 and P4 generation and the expression of steroidogenic enzymes including Star, Cyp19a1 and Cyp11a1 induced by PA or TG (Fig. 10a-f).

\section{Discussion}

PA is a common saturated fatty acid and the PA level in mammalian FF is reported to be approximately $10^{-4} \mathrm{M}$. A previous study showed that PA induces granulosa cell apoptosis and inhibits steroidogenesis [13]. Our previous studies found that ER stress is related to granulosa cell apoptosis and steroidogenesis $[15,16]$. In addition, some studies have reported that melatonin inhibits cell apoptosis through

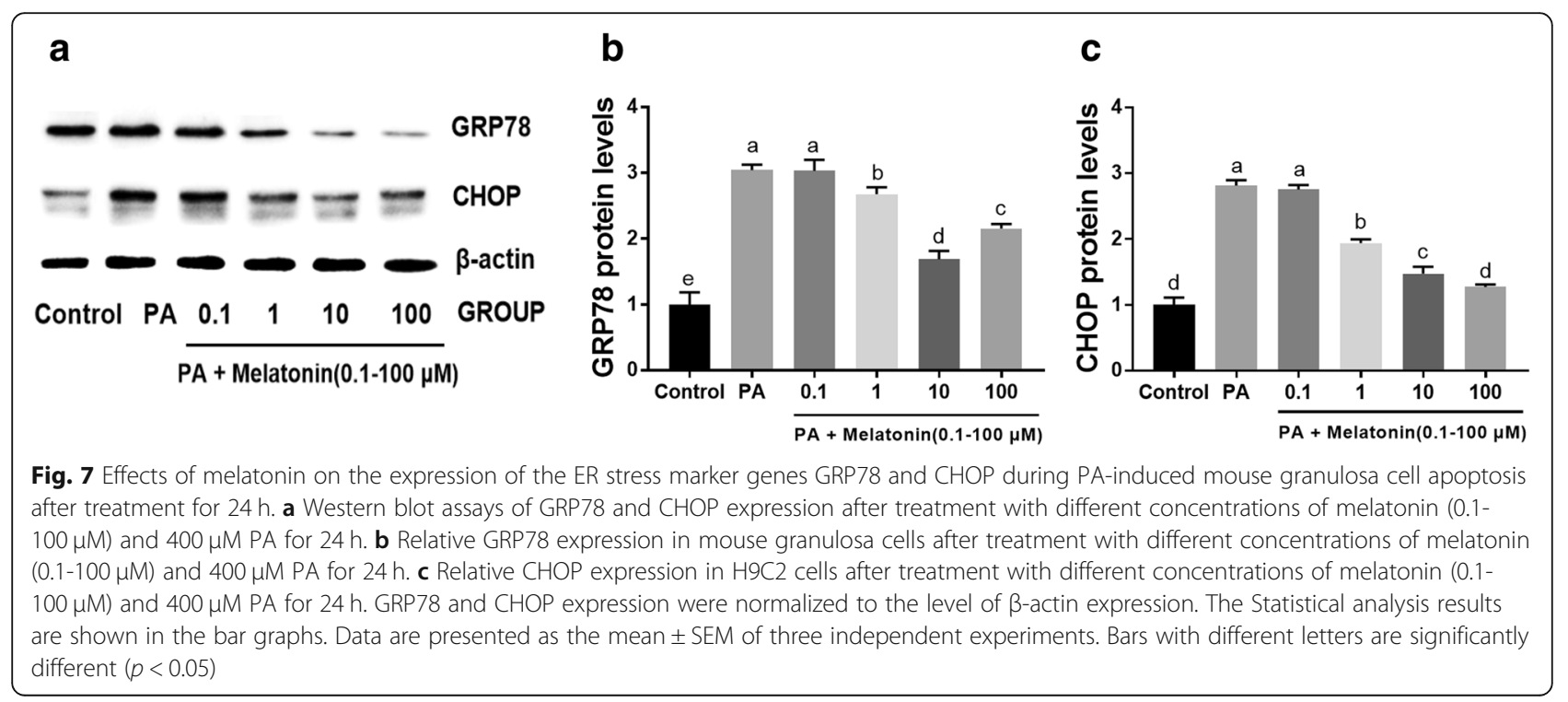




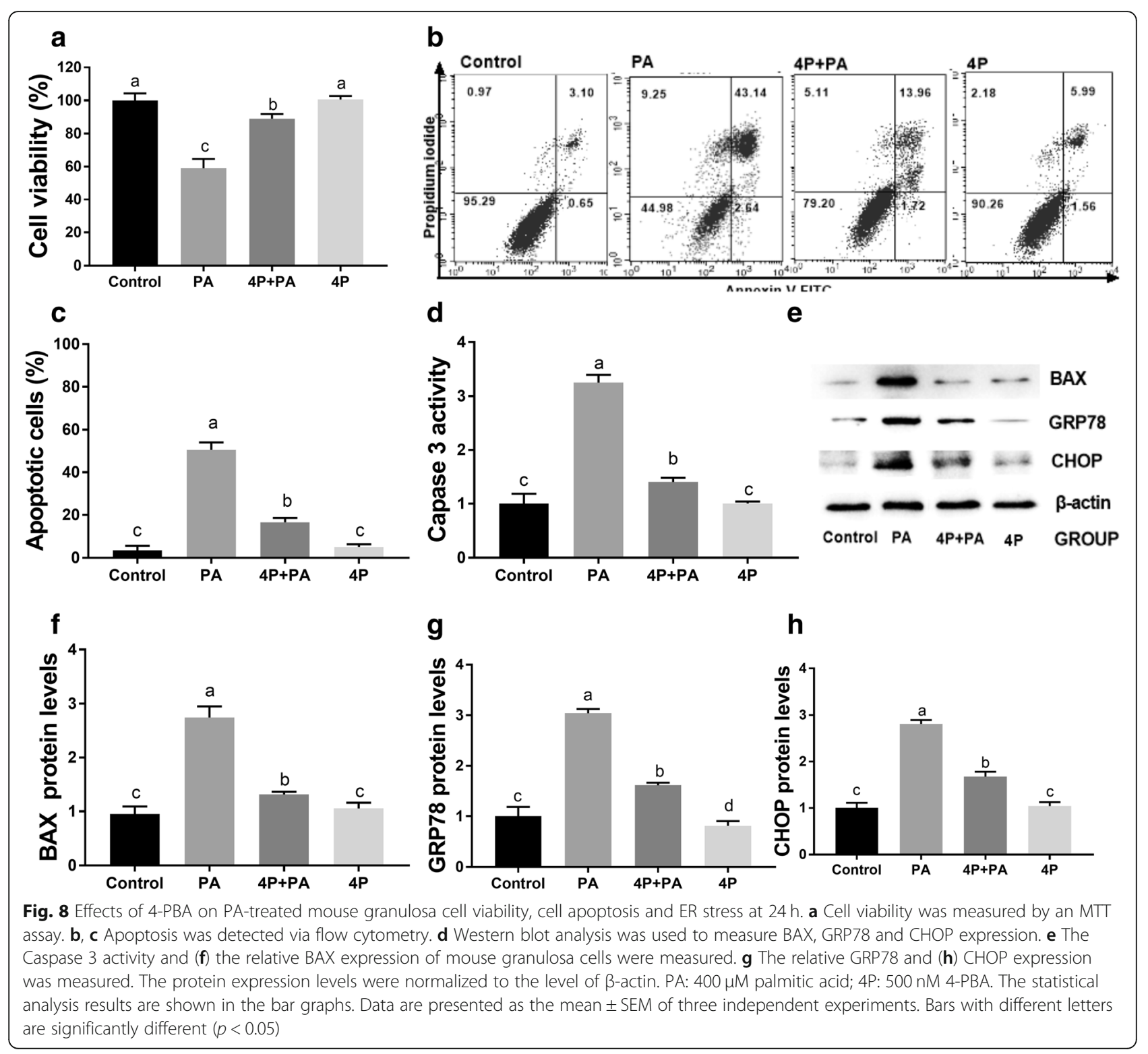

attenuating ER stress [19-21]. In this study, we showed that PA-induced granulosa cell apoptosis and steroidogenesis downregulation occur via ER stress and that melatonin can rescue this process.

We first detected the effects of different concentrations of PA on cell viability and apoptosis. The data from our study showed that cell viability was significantly decreased and apoptosis was induced during in vitro culture with PA. Our study was consistent with a previous study showing that PA markedly inhibits the proliferation of human granulosa cells in a dose-dependent manner [13]. We also measured the expression of apoptosis-related genes (Caspase 3 and BAX) during PA treatment. Caspase 3 acts as an executioner in caspase-mediated apoptosis, and the expression of Caspase 3 positively correlates with the rate of apoptosis in cells [33]. Moreover, BAX, a member of the
BCL2 family, has a proapoptotic effect [34]. In the present study, we found that Caspase 3 activation and BAX expression were upregulated after PA treatment. Based on these results, we concluded that PA can regulate Caspase 3 activation and BAX expression to affect cell apoptosis in mouse granulosa cells.

Furthermore, we detected GRP78 and CHOP expression when cells were cultured with $100-800 \mu \mathrm{M}$ PA for $24 \mathrm{~h}$. The results showed that PA treatment induced the expression of GRP78 and CHOP, which indicated that PA activates the ER stress pathway in cultured mouse granulosa cells. GRP78 is an ER stress-response protein, and its expression is a typical marker of ER stress activation. Our previous results showed that PA triggers ER stress and then induces apoptosis though CHOP activation in Saos-2 cells [18]. In addition, this result is consistent with the results of other studies that showed 

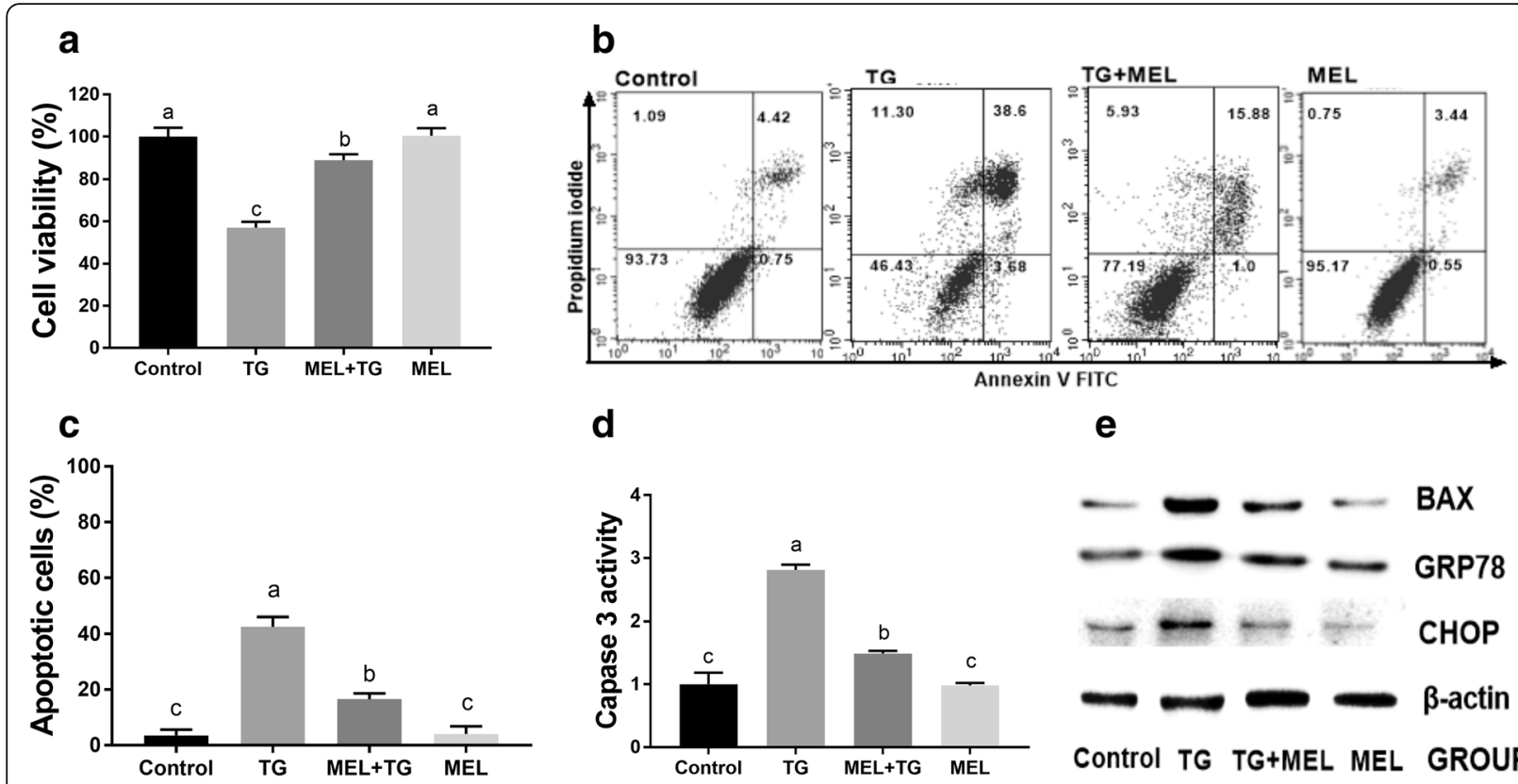

d

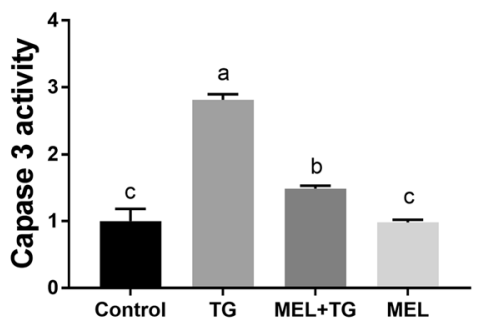

g

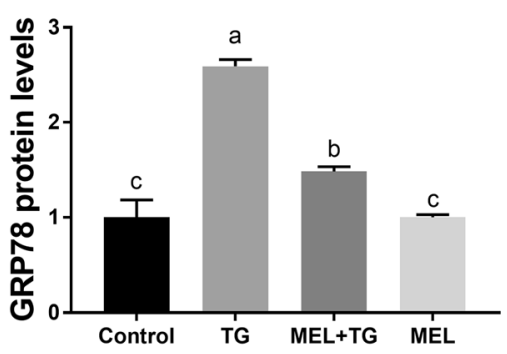

e

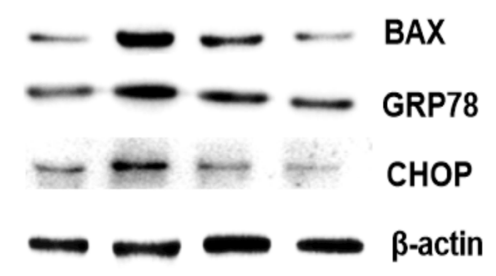

Control TG TG+MEL MEL GROUP

h

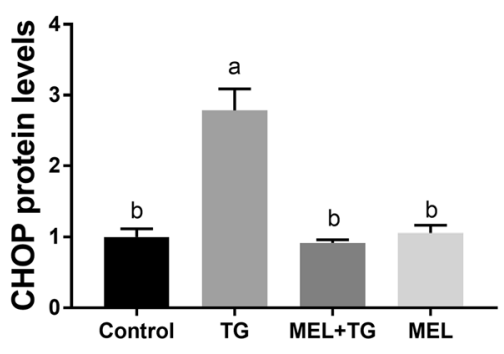

Fig. 9 Effects of melatonin on TG-treated mouse granulosa cell viability, cell apoptosis and ER stress at $24 \mathrm{~h}$. a Cell viability measured by an MTT assay. b, c Apoptosis detected via flow cytometry. $\mathbf{d}$ Western blot assays of BAX, GRP78 and CHOP expression. e Caspase 3 activity of H9C2 cells. $\mathbf{f}$ Relative BAX expression. $\mathbf{g}$ Relative GRP78 expression. $\mathbf{h}$ Relative CHOP expression. The protein expression levels were normalized to the $\beta$-actin level. PA: $400 \mu \mathrm{M}$ palmitic acid; TG: $500 \mathrm{nM}$ thapsigargin; MEL: $10 \mu \mathrm{M}$ melatonin; 4P: $500 \mathrm{nM}$ 4-PBA. The statistical analysis results are shown in the bar graphs. Data are presented as the mean \pm SEM of three independent experiments. Bars with different letters are significantly different $(p<0.05)$

that PA induces ER stress and apoptosis in hepatoma cells [35] and myocardial cells [34]. The present study further demonstrated PA-induced ER stress in mouse granulosa cells. To our knowledge, this is the first study to demonstrate that ER stress can be induced by PA in granulosa cells, which implies that ER stress is involved in PA-induced granulosa cell apoptosis.

Melatonin is an important endogenous hormone and exists in mammalian FF. Physiologically, the concentration of melatonin in mammalian follicular fluid is reported to be approximately $10^{-11} \mathrm{M}$. However, the melatonin level in the FF is reported to be dynamic and reaches its zenith in the preovulatory follicle [36-40]. Numerous studies have revealed that melatonin exerts various biological effects, such as antioxidative [41], anti-inflammatory [42] and anti-apoptotic effects [43].
Furthermore, ER stress plays a key role in the process of cell injury, and some studies also reported that melatonin inhibits cell apoptosis via the ER stress pathway [19-21]. Interestingly, there is evidence suggesting that that intrafollicular melatonin concentration decreased as follicular atresia progressed whereas the percentage of apoptotic granulosa cells increased [26]. Thus, we suspected that dynamic change of melatonin and PA level in FF may be closely related to granulosa cell apoptosis. Therefore, we identified the effects of melatonin on granulosa cell apoptosis and ER stress. Our results suggested that melatonin obviously inhibited PA- or TG-induced GRP78 and CHOP expression. Furthermore, melatonin remarkably inhibited PA- or TG-induced mouse granulosa cell apoptosis and the expression of Caspase 3 and BAX, suggesting that melatonin can 


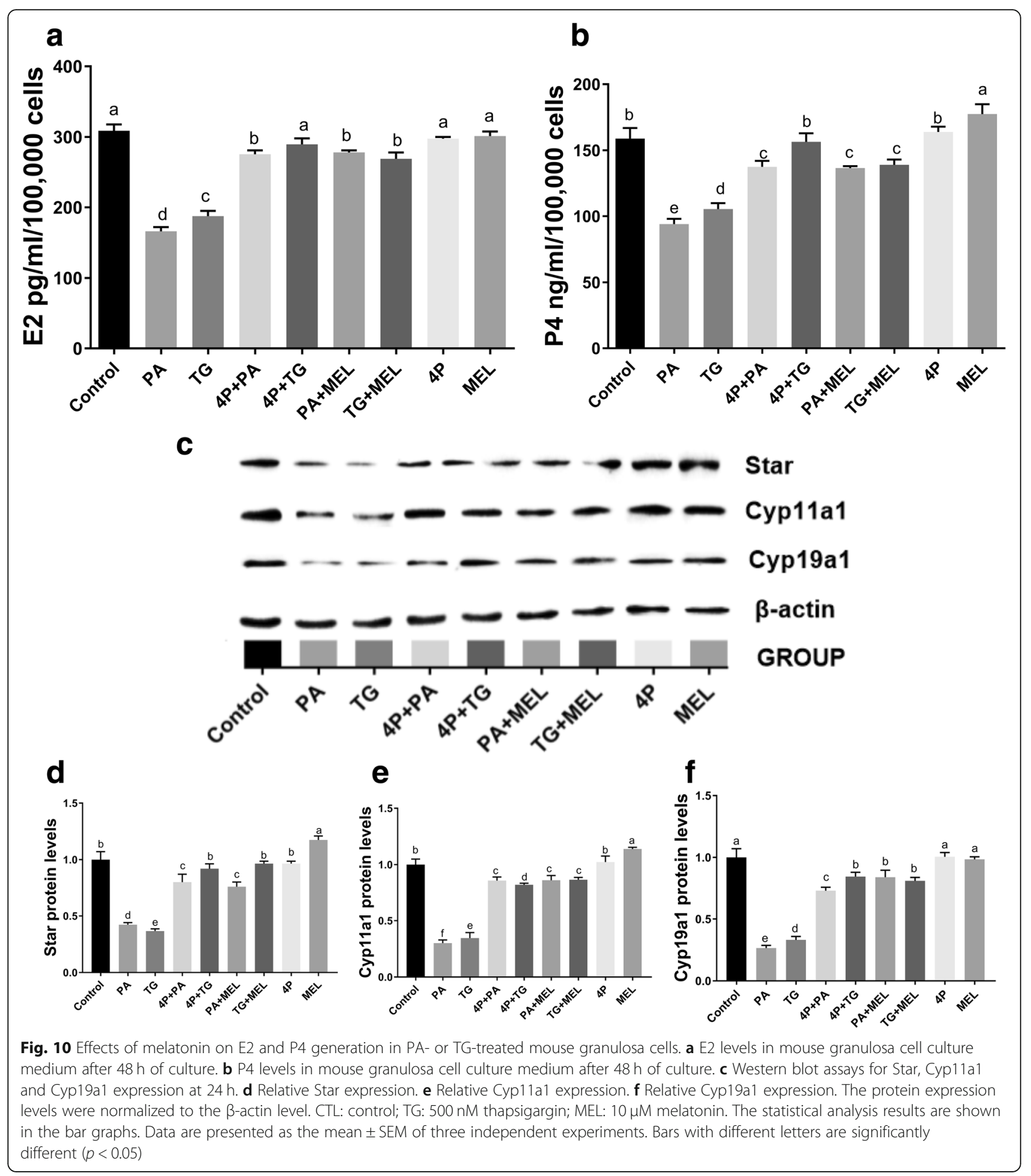

protect cells against PA and ER stress-induced cell apoptosis. To further confirm the role of ER stress in PA-induced granulosa cell apoptosis, we added the ER stress inhibitor 4-PBA to culture medium containing PA. The results showed that 4-PBA and melatonin both suppressed PA-induced cell apoptosis and decreased the expression of GRP78 and CHOP. This date further confirmed the fact that melatonin significantly reduced the cell apoptosis induced by PA via the ER stress pathway.

Granulosa cells play an important role in hormonal synthesis in females. Compared with the control treatment, PA treatment decreased E2 and P4 expression. 
The possible reason for the reductions could be the decreases in the levels of Star (the protein associated with the transport of cholesterol across the mitochondrial membrane), Cyp11a1 (the monooxygenase that catalyzes cholesterol and steroid synthesis), and Cyp19a1 (the enzyme responsible for androgen aromatization to estrogen) [31] shown in our results. Previous studies have demonstrated that E2 and P4 are indispensable for maintaining the normal physiological function of the ovary [44]. Thus, we infer that PA may induce follicular atresia and affect ovulation by regulating $\mathrm{P} 4$ and E2 production in granulosa cells.

In agreement with its effect on PA-induced cell apoptosis, melatonin and 4-PBA also reverse the PA-mediated inhibition of hormone secretion. We also found that the PA-induced decrease in hormone secretion-related protein expression was partly inhibited by melatonin or 4-PBA, indicating that melatonin improves hormone secretion in PA- or TG-treated mouse granulosa cells. This result further confirmed the findings of previous studies that showed that melatonin weakens ER stress [19-21] and ER stress is involved in granulosa cell apoptosis [15, $16]$ and hormone secretion [44].

The concentration of melatonin used in the present study is $10^{-6} \mathrm{M}$ which seems to be higher than physical level. However, we thought that the high concentration of melatonin used in this study could reflect the in vivo conditions. As we known, melatonin is considered as a broad-spectrum antioxidant. After melatonin reacts with ROS, the melatonin metabolites are produced and accumulated in vivo. Subsequently, the melatonin metabolites also work as antioxidants, resulting in melatonin and melatonin metabolites working together as powerful antioxidants in vivo [43]. Accumulating evidence indicates that PA increases the production of reactive oxygen species (ROS) in granulosa cells and that oxidative stress is essential for the induction of ER stress in granulosa cells [45]. Therefore, we speculated that PA might induce oxidative stress by stimulating the generation of ROS, destroying the antioxidant capacity, and subsequently triggering ER stress and apoptosis in granulosa cells. Melatonin and its metabolites may effectively decrease the PA-induced generation of ROS to mitigate oxidative stress, protecting granulosa cells from PA-induced apoptosis through ER stress.

\section{Conclusion}

In summary, our results initially demonstrated that PA-induced cell mouse granulosa cell apoptosis occurs via the ER stress pathway. Furthermore, melatonin has the potential to protect mouse granulosa cells from PA-induced cell apoptosis and hormone expression downregulation. Therefore, melatonin is a potent agent that could be exploited as a potential intervention in the prevention of some reproductive abnormalities, especially in female infertility induced by saturated fatty acids.

\section{Additional file}

Additional file 1: Table S1. Antibody details. (DOCX $16 \mathrm{~kb})$

\begin{abstract}
Abbreviations
ATF6: activating transcription factor-6; BAX: B-cell lymphoma-2 (BCL-2) associated $X$ protein; BCA: bicinchoninic acid; CHOP: CCAAT/enhancer binding protein homologous protein; DMSO: dimethyl sulfoxide; E2: estrogen; ER: endoplasmic reticulum; FF: follicular fluid; GRP78: glucose-regulated protein 78; IRE-1: inositol-requiring enzyme-1; MTT: methyl thiazolyl tetrazolium; P4: progesterone; PA: palmitic acid; PBS: phosphate buffer solution; PERK: protein kinase RNA (PKR)-like ER kinase; PMSG: pregnant mare serum gonadotrophin; PVDF: polyvinylidene difluoride;

RIPA: radioimmunoprecipitation assay; ROS: reactive oxygen species; TBST: Tris-buffered saline-Tween-20; TG: thapsigargin; UPR: unfolded protein response
\end{abstract}

\section{Funding}

This study was supported by the Project of Science and Technology of the Jiangxi Provincial Education Department (GJJ170966), the Project of the Health Commission of Jiangxi Province (20193010; 20197217), the Natural Science Research Project of the Education Department of the Guizhou Province of China (KY2018419), the Scientific Research Project of Qiannan Normal University for Nationalities (qnsyrc201610, QNSY2018BS018), the Qiannan Agricultural Science and Technology Program of the Qiannan Science and Technology Bureau (201721), the Research and Innovation Team Foundation of the Guizhou Province Education Department (201568), the Key Support Project for Botany in Guizhou (ZDXK201623) and the Key Support Project for Biology in Qiannan Normal University for Nationalities.

\section{Availability of data and materials}

The data obtained from this study are available from the corresponding author upon reasonable request.

\section{Authors' contributions}

$\mathrm{CZ}$ and $\mathrm{YL}$ designed the study and prepared the manuscript. $\mathrm{CZ}$ performed the experiments. LL and WD assisted in the data analysis and helped prepare the manuscript. All authors read and approved the final manuscript.

\section{Ethics approval and consent to participate}

All procedures were approved by the Committee for the Ethics on Animal Care and Experiments of Jiujiang University (approval No. SYXK(GAN)20170001).

\section{Consent for publication}

All authors agree to the submission of this article for publication.

\section{Competing interests}

The authors declare that they have no competing interests.

\section{Publisher's Note}

Springer Nature remains neutral with regard to jurisdictional claims in published maps and institutional affiliations.

\section{Author details}

${ }^{1}$ College of Biological Science and Agriculture, Qiannan Normal University for Nationalities, Guizhou 558000, Duyun, China. ${ }^{2}$ Affiliated Hospital of Jiujiang University, Jiujiang University, Jiujiang 332000, Jiangxi, China. ${ }^{3}$ Key Laboratory of System Bio-medicine of Jiangxi Province, Jiujiang University, Jiujiang 332000, Jiangxi, China. ${ }^{4}$ College of Basic Medical Science, Jiujiang University, Jiujiang 332000, Jiangxi, China. 


\section{Received: 12 January 2019 Accepted: 30 April 2019}

\section{Published online: 10 May 2019}

\section{References}

1. Yu Y, Cai Z, Zheng J, Chen J, Zhang X, Huang XF, et al. Serum levels of polyunsaturated fatty acids are low in Chinese men with metabolic syndrome, whereas serum levels of saturated fatty acids, zinc, and magnesium are high. Nutr Res. 2012;32:71.

2. Dunning KR, Russell DL, Robker RL. Lipids and oocyte developmental competence: the role of fatty acids and beta-oxidation. Reproduction. 2014; 148:R15-27.

3. Leroy JL, Vanholder T, Mateusen B, Christophe A, Opsomer G, de Kruif A, et al. Non-esterified fatty acids in follicular fluid of dairy cows and their effect on developmental capacity of bovine oocytes in vitro. Reproduction. 2005; 130:485-95.

4. Valckx SD, Arias-Alvarez M, De Pauw I, Fievez V, Vlaeminck B, Fransen E, et al. Fatty acid composition of the follicular fluid of normal weight, overweight and obese women undergoing assisted reproductive treatment: a descriptive cross-sectional study. Reprod Biol Endocrinol. 2014;12:13.

5. Aardema H, Gadella BM, van de Lest CH, Brouwers JF, Stout TA, Roelen BA et al. Free fatty acid levels in fluid of dominant follicles at the preferred insemination time in dairy cows are not affected by early postpartum fatty acid stress. J Dairy Sci. 2015;98:2322-36.

6. Mirabi P, Chaichi MJ, Esmaeilzadeh S, Ali Jorsaraei SG, Bijani A, Ehsani M, et al. The role of fatty acids on ICSI outcomes: a prospective cohort study. Lipids Health Dis. 2017:16:18.

7. Niu Z, Lin N, Gu R, Sun Y, Feng Y. Associations between insulin resistance, free fatty acids, and oocyte quality in polycystic ovary syndrome during in vitro fertilization. J Clin Endocrinol Metab. 2014;99:E2269-76.

8. Leroy JL, Genicot G, Donnay I, Van Soom A. Evaluation of the lipid content in bovine oocytes and embryos with nile red: a practical approach. Reprod Domest Anim. 2005;40:76-8.

9. McKeegan PJ, Sturmey RG. The role of fatty acids in oocyte and early embryo development. Reprod Fertil Dev. 2011;24:59-67.

10. M'Baye M, Hua G, Khan HA, Yang L. RNAi-mediated knockdown of INHBBincreases apoptosis and inhibits steroidogenesis in mouse granulosacells. J Reprod Dev. 2015;61:391-7.

11. Jiang JY, Cheung CK, Wang Y, Tsang BK. Regulation of cell death and cell survival gene expression during ovarian follicular development and atresia. Front Biosci. 2003;8:d222-37.

12. Matsuda F, Inoue N, Manabe N, Ohkura S. Follicular growth and atresia in mammalian ovaries: regulation by survival and death of granulosa cells. J Reprod Dev. 2012;58:44-50

13. Mu YM, Yanase T, Nishi Y, Tanaka A, Saito M, Jin CH, et al. Saturated FFAs, palmitic acid and stearic acid, induce apoptosis in human granulosa cells. Endocrinology. 2001;142:3590-7.

14. Vanholder T, Leroy JL, Soom AV, Opsomer G, Maes D, Coryn M, et al. Effect of non-esterified fatty acids on bovine granulosa cell steroidogenesis and proliferation in vitro. Anim Reprod Sci. 2005;87:33-44.

15. Yang $Y$, Lin $P$, Chen $F$, Wang $A$, Lan $X$, Song $Y$, et al. Luman recruiting factor regulates endoplasmic reticulum stress in mouse ovarian granulosa cell apoptosis. Theriogenology. 2013;79:633-9.

16. Lin $\mathrm{P}$, Yang $Y, L i X$, Chen F, Cui C, Hu L, et al. Endoplasmic reticulum stress is involved in granulosa cell apoptosis during follicular atresia in goat ovaries. Mol Reprod Dev. 2012;79:423-32.

17. Yang $Y$, Pei $X$, Jin $Y$, Wang $Y$, Zhang $C$. The roles of endoplasmic reticulum stress response in female mammalian reproduction. Cell Tissue Res. 2016; 363:589-97.

18. Yang L, Guan GP, Lei $\sqcup$, Lv QZ, Liu SY, Zhan XW, et al. Palmitic acid induces human osteoblast-like Saos-2 cell apoptosis via endoplasmic reticulum stress and autophagy. Cell Stress Chaperones. 2018;23:1283-94.

19. Yu L, Li B, Zhang M, Jin Z, Duan W, Zhao G, et al. Melatonin reduces PERKelF2a-ATF4-mediated endoplasmic reticulum stress during myocardial ischemia-reperfusion injury: role of RISK and SAFE pathways interaction. Apoptosis. 2016;21:809-24.

20. Wongprayoon P, Govitrapong P. Melatonin protects SH-SY5Y neuronal cells against methamphetamine-induced endoplasmic reticulum stress and apoptotic cell death. Neurotox Res. 2016;31:1-10.

21. Ji YL, Wang H, Meng C, Zhao XF, Zhang C, Zhang Y, et al. Melatonin alleviates cadmium-induced cellular stress and germ cell apoptosis in testes. J Pineal Res. 2012;52:71-9.
22. El-Raey M, Geshi M, Somfai T, Kaneda M, Hirako M, Abdel-Ghaffar AE, et al. Evidence of melatonin synthesis in the cumulus oocyte complexes and its role in enhancing oocyte maturation in vitro in cattle. Mol Reprod Dev. 2011;78:250-62.

23. Kang JT, Koo OJ, Kwon DK, Park HJ, Jang G, Kang SK, et al. Effects of melatonin on in vitro maturation of porcine oocyte and expression of melatonin receptor RNA in cumulus and granulosa cells. J Pineal Res. 2009; 46:22-8.

24. Reiter RJ, Rosales-Corral SA, Manchester LC, Tan DX. Peripheral reproductive organ health and melatonin: ready for prime time. Int J Mol Sci. 2013;14: $7231-72$.

25. Shi JM, Tian XZ, Zhou GB, Wang L, Gao C, Zhu SE, et al. Melatonin exists in porcine follicular fluid and improves in vitro maturation and parthenogenetic development of porcine oocytes. J Pineal Res. 2009;47:318-23.

26. He $Y$, Deng $H$, Jiang $Z$, Li Q, Shi M, Chen $H$, et al. Effects of melatonin on follicular atresia and granulosa cell apoptosis in the porcine. Mol Reprod Dev. 2016;83:692-700.

27. Papis K, Poleszczuk O, Wenta-Muchalska E, Modlinski JA. Melatonin effect on bovine embryo development in vitro in relation to oxygen concentration. J Pineal Res. 2007:43:321-6.

28. Morgan MA, Silavin SL, Wentworth RA, Figueroa JP, Honnebier BO, Fishburne $\mathrm{Jl}$, et al. Different patterns of myometrial activity and 24-h rhythms in myometrial contractility in the gravid baboon during the second half of pregnancy. Biol Reprod. 1992;46:1158-64.

29. Ronnberg L, Kauppila A, Leppaluoto J, Martikainen H, Vakkuri O. Circadian and seasonal variation in human preovulatory follicular fluid melatonin concentration. J Clin Endocrinol MeTable. 1990;71:492-6.

30. Wang SJ, Liu WJ, Wu CJ, Ma FH, Ahmad S, Liu BR, et al. Melatonin suppresses apoptosis and stimulates progesterone production by bovine granulosa cells via its receptors (MT1 and MT2). Theriogenology. 2012;78: $1517-26$.

31. Lei LJ, Han F, Cui QY, Liao WF, Liu H, Guan GP, et al. IRS2 depletion inhibits cell proliferation and decreases hormone secretion in mouse granulosa cells. J Reprod Dev. 2018;64:409-16.

32. Chen F, Li Q, Zhang Z, Lin P, Lei L, Wang A, et al. Endoplasmic reticulum stress cooperates in zearalenone-induced cell death of RAW 264.7 macrophages. Int J Mol Sci. 2015;16:19780-95.

33. Zhu Q, Yang J, Zhu R, Jiang X, Li W, He S, et al. Dihydroceramidedesaturase-1-mediated caspase 9 activation through ceramide plays a pivotal role in palmitic acid-induced HepG2 cell apoptosis. Apoptosis. 2016; 21:1033-44

34. He Y, Zhou L, Fan Z, Liu S, Fang W. Palmitic acid, but not highglucose, induced myocardial apoptosis is alleviated by $\mathrm{N}$-acetylcysteine due to attenuated mitochondrial-derived ROS accumulation-induced endoplasmic reticulum stress. Cell Death Dis. 2018;9:568.

35. Zhang Y, Miao LS, Zhang HJ, Wu G, Zhang ZN, Lv JR. Chlorogenic acid against palmitic acid in endoplasmic reticulum stress-mediated apoptosis resulting in protective effect of primary rat hepatocytes. Lipids Health Dis. 2018;17:270.

36. Nakamura $\mathrm{Y}$, Tamura $\mathrm{H}$, Takayama $\mathrm{H}$, Kato $\mathrm{H}$. Increased endogenous level of melatonin in preovulatory human follicles does not directly influence progesterone production. Fertil Steril. 2003;80:1012-6.

37. Tamura H, Nakamura Y, Korkmaz A, Manchester LC, Tan DX, Sugino N, et al. Melatonin and the ovary: physiological and pathophysiological implications. Fertil Steril. 2009;92:328-43.

38. Tamura H, Takasaki A, Miwa I, Taniquchi K, Maekawa R, Asada H, et al. Oxidative stress impairs oocyte quality and melatonin protects oocytes from free radical damage and improves fertilization rate. J Pineal Res. 2008:44:280-7.

39. Tamura H, Takasaki A, Taketani T, Tanabe M, Kizuka F, Lee L, et al. The role of melatonin as an antioxidant in the follicle. J Ovarian Res. 2012;5:5.

40. Tamura H, Takasaki A, Taketani T, Tanabe M, Kizuka F, Lee L, et al. Melatonin as a free radical scavenger in the ovarian follicle. Endocr J. 2013:60:1-13.

41. Remiao MH, Lucas CG, Domingues WB, Silveira T, Barther NN, Komninou ER, et al. Melatonin delivery by nanocapsules during in vitro bovine oocyte maturation decreased the reactive oxygen species of oocytes and embryos. Reprod Toxicol. 2016;63:70-81.

42. Mayo JC, Sainz RM, Tan DX, Hardeland R, Leon J, Rodriguez C, et al. Anti-inflammatory actions of melatonin and its metabolites, $\mathrm{N1}$-acetylN2-formyl-5-methoxykynuramine (AFMK) and n1-acetyl-5methoxykynuramine (AMK), in macrophages. J Neuroimmunol. 2005; 165:139-49. 
43. Tanabe M, Tamura H, Taketani T, Okada M, Lee L, Tamura I, et al. Melatonin protects the integrity of granulosa cells by reducing oxidative stress in nuclei, mitochondria, and plasma membranes in mice. J Reprod Dev. 2015; 61:35-41.

44. Xiong YJ, Chen HT, Lin PF, Wang AH, Wang L, Jin YP. ATF6 knockdown decreases apoptosis, arrests the $S$ phase of the cell cycle, and increases steroid hormone production in mouse granulosa cells. Am J Phys Cell Phys. 2017;312:C341-53.

45. Liu H, Zhang $X$, Zhang $S$, Huang $H$, Wu J, Wang $Y$, et al. Oxidative stress mediates microcystin-LR-induced endoplasmic reticulum stress and autophagy in KK-1 cells and C57BL/6 mice ovaries. Front Physiol. 2018;9:1058.

Ready to submit your research? Choose BMC and benefit from:

- fast, convenient online submission

- thorough peer review by experienced researchers in your field

- rapid publication on acceptance

- support for research data, including large and complex data types

- gold Open Access which fosters wider collaboration and increased citations

- maximum visibility for your research: over $100 \mathrm{M}$ website views per year

At $\mathrm{BMC}$, research is always in progress.

Learn more biomedcentral.com/submissions 